\title{
Pattern of Flail Chest Injury Secondary to Blunt Chest Trauma in Menoufia University Hospital (a Prospective Study)
}

\author{
Ola Sweilum and Reham Hassan El Farouny ${ }^{1}$
}

${ }^{1}$ Forensic Medicine and Clinical toxicology, Faculty of Medicine Menoufia University, Menoufia, Egypt.

\begin{abstract}
Flail chest injury is a condition usually resulting from a blunt trauma with a great force to the chest wall causing multiple rib fractures with segmental chest wall instability and leading to significant morbidity and mortality. Flail chest is frequently accompanied by other injuries.

This study aims to assess the pattern of traumatic flail chest injury secondary to blunt chest trauma, in patients admitted to Menoufia University Hospital.

Demographic criteriaof the patients,type and cause of trauma, data about duration of intensive care unit (ICU) stay, hospital stay, time interval to returnto work (complete recovery), occurrence of chest wall deformity, new injury severity score (NISS) and mortality rate, were all collected and studied.

Conclusion: Flail chest injury represented $8.2 \%$ of all blunt chest trauma admitted to Menoufia University Hospital during the period of thisstudy. Road traffic accident (RTA) is considered the first cause of flail chest injury. The NISS is a significant way for correlation between the condition of the patients and the mortality rate.
\end{abstract}

Key words Flail chest, NISS, Mortality, road traffic accidents.

\section{Introduction}

lunt injury to the chest is one of the commonest
causes of mortality and morbidity in trauma
patients. It ranges from simple abrasion and contusion to more life-threatening lung injuries. It is more frequent than sharp and penetrating injuries (Battle and Evans, 2015)

Flail chest injury is a condition usually resulting from a blunt high impact trauma to the chest causing multiple rib fractures with segmental chest wall instability and leading to significant morbidity and mortality (Athanassiadi et al., 2010; Ciraulo et al., 1994) . It occurs in approximately $10 \%$ of patients with chest trauma (Ciraulo et al., 1994) and it is a very serious complication (Evman et al., 2015). Diagnosis of flail chest is mainly clinical. This can confirmed radiologically either by plain chest radiogram or computed tomography (Coughlin et al., 2016).

The most common mechanisms of trauma resulting in flail chest injury are: road traffic accidents (RTA), fall from height and assault. Less severe trauma can also cause flail chest injuries in special cases as elderly persons or those with underlying pathology of the ribs, as severe osteoporosis or multiple myeloma (Marasco et al., 2013).

Flail chest is usually associated with other chest injuries such as: hemothorax, pneumothorax, pulmonary contusion, or any combination of these. Pneumonia and respiratory failure are common flail chest complications (Allen and Coates, 1996). Flail chest injuries mayresult in long-term complications such as chronic pain, dyspnea and chest wall deformity which can affect the quality of life (Marasco et al., 2013).

\section{Aim of the work}

This study aims to assess the pattern of traumatic flail chestinjury secondary to blunt chest trauma; its causes, morbidity and mortality in patientsadmitted to Menoufia University Hospital.

\section{Patients and Methods}

This was a prospective study carried out on 42 patientswith flail chest secondary to blunt trauma, arriving at emergency department of Menoufia University Hospitals, Egypt, during the period between $1^{\text {st }}$ of July 2015 to the end of December 2016.

Ethical approval was obtained from the ethical committee at Menoufia University hospital and consent was waived.

On admission, all patients underwenthistory taking, clinical examination and plain chest radiogram on admission and most of them also underwent computed tomography of the chest. Additional investigations were done depending on the presence of other associated injuries.

Patient's demographic data, data about the 
injury (number and side of rib fractures, and associated stay, hospital stay, time needed by the patient to returns work (the complete recovery time), occurrence of chest wall deformity and mortality rate, were collected and studied.

Severity of injury was assessed using the New Injury Severity Score (NISS), which was calculated from the square of the three highest abbreviated injury score (AIS) regardless of the anatomical body regions (Osler et al., 1997; Stevenson et al., 2001).The AIS is an anatomical scoring system, where the whole body is divided into six regions (head, face, chest, abdomen, extremities (including pelvis), external), each injury in any region will be addressed by score ranked 1 to 6 , with 1 being minor, 5 severe, and 6 a non-survivable injury (Baker, et al.1974).The sum of square of the three highest abbreviated injury score (AIS) regardless of the anatomical body regions will represent the NISS as total score takes values from 0 to 75 where the score of 1-9 considered minor, 10-15 moderate,16-24 severe and $>25$ is critical (Stevenson et al., 2001, Balogh, et al., 2003).

The patients included in this study were divided into three groups, as per the mechanism of trauma: these were road traffic accident (RTA), fall from height and assault. All data were compared and analyzed.

\section{Statistical analysis:}

Statistical analysis was performed using SPSS Version 17. Differences between groups were explored using ANOVA test for continuous variables and a Chi-square test for categorical variables. Differences were considered significant if the P Value was less than 0.05 .

\section{Results}

From 510 cases of blunt chest trauma admitted to Menoufia university hospital during the period of study, 42 cases had flail chest injury secondary to blunt trauma (8.2\%). Of all cases, 32 (76.2\%) were males.

In Road traffic accidents (RTA) group (32 patients),majority of them were pedestrians (22 cases about 69\%), others were drivers and motorcyclist. $78 \%$ patients of RTA patients were males and 7 patients (22\%) were females. In fall group (6 patients), 4 (67\%) were males and 2 (33\%) were females. In assault group (4 patients, 3 patients (75\%) were males and only one female patient (25\%). The differences between these three groups regardinggender were not statistically significant (P value: 0.831) (Table 1).

The mean patient's age \pm SD was $37.10 \pm$ 13.69 years, varying from $38.25 \pm 13.77$ in RTA group and $40.33 \pm 12.21$ in Fall group and $23 \pm 7.44$ in Assault group. There was no statistically significant difference between the three groups regarding age (p value: 0.088 ) chest injuries), duration of intensive care unit (ICU) (Table 1).

The mean number of fractured ribs \pm SD was $5.40 \pm 1.80$ ribs. In RTA group, this was $5.94 \pm 1.68$ ribs. In Fall group $3.50 \pm 0.84$ ribs and in Assault group the mean number of fractured ribs \pm SD was $4.0 \pm 0.82$. These differences between groups regarding number of rib fractured were statistically highly significant ( $p$ value 0.001) (Table 2).

The rib fractures in the fall and assault groups were all unilateral. In RTA 29 patients (90.6\%) were unilateral and only 3 patients $(9.4 \%)$ had bilateral rib fracture. The difference between the three groups regarding the side of rib fracture were not statistically significant (P value: 0.86) (Table 2).

As regards associated chest injuries, lung contusion was the most common one (35.7\%) followed by haemothorax (28.57\%), hemopneumothorax (21.43\%) and pneumothorax (14.29\%). In relation to the mechanism of trauma, in RTA, lung contusion was the commonest associated injury, with incidence of $40.6 \%$. In fall group, haemothorax was the commonest associated injury; whilepneumothorax was the commonest associated injury in the assault group and represented half of these cases (Table 3).

The duration of Intensive care unit (ICU) stay, hospital stay and time interval to return to work (complete recovery) was all longest in the RTA group with mean \pm SD of $6.75 \pm 3.75$ days, $13.66 \pm 4.59$ days, and $4.47 \pm 1.08$ weeks respectively. This is followed by the fall group with mean \pm SD of $5.33 \pm 1.37$ days, 9.5 \pm 1.64 days, and $3.67 \pm 0.82$ weeks respectively (Table $3)$. The difference between the three groups was statistically significant regarding the duration of ICU stay (P-value: 0.05), hospital stay (P-value: 0.02), and interval to return to work (P-value: 0.03) (Table 4).

RTA was responsible for $90.9 \%$ of chest wall deformities, compared with9.1\% was due to fall; this difference was not statistically significant ( $\mathrm{P}$ value 0.35).

As high significant relation had been found between the mechanism of injury and the new injury severity score(NISS), as the largest percent among RTA (65.6\%) had critical NISS scoring,2 (6.25\%) serious, and $9(28.13 \%)$ were severe. While $75 \%$ of assault and $50 \%$ of fall cases were severe, while serious cases were divided into $33.33 \%$ by fall and $25 \%$ by assault (Table 5).

The overall mortality rate was $21.4 \%$. Mortality was recorded only with RTA cases. There were no deaths in flail chest injuries resulting from fall and assaults (Table 6).According to NISS, mortality was associated mainly with critical cases(88.9\%), this relation was statistically significant ( $P$ value 0.05 ) (Table 7) (figure 1). 
Table 1: Chi square statistical analysis offlail chest injury patients admitted to Menoufia University Hospital as regards age and gender.

\begin{tabular}{|c|c|c|c|c|}
\hline & $\begin{array}{c}\text { RTA } \\
\mathbf{N}=\mathbf{3 2}\end{array}$ & $\begin{array}{c}\text { Fall } \\
\mathbf{N = 6}\end{array}$ & $\begin{array}{c}\text { Assault } \\
\mathbf{N}=\mathbf{4}\end{array}$ & $\boldsymbol{p}$-value \\
\hline Age & $38.25 \pm 13.77$ & $40.33 \pm 12.21$ & $23 \pm 7.44$ & 0.088 \\
\hline Sex & & & & \\
Male & $25(78 \%)$ & $4(67 \%)$ & $3(75 \%)$ & 0.831 \\
Female & $7(22 \%)$ & $2(33 \%)$ & $1(25 \%)$ & \\
\hline
\end{tabular}

Table 2:Chi square statistical analysis offlail chest injury patients admitted to Menoufia University Hospital regarding characters of fractured ribs.

\begin{tabular}{|c|c|c|c|c|}
\hline & $\begin{array}{c}\text { RTA } \\
\mathbf{N}=\mathbf{3 2}\end{array}$ & $\begin{array}{c}\text { Fall } \\
\mathbf{N = 6}\end{array}$ & $\begin{array}{c}\text { Assault } \\
\mathbf{N}=\mathbf{4}\end{array}$ & $\boldsymbol{p}$-value \\
\hline $\begin{array}{c}\text { Number of fractured ribs } \\
\text { Mean } \pm \text { SD }\end{array}$ & $5.94 \pm 1.68$ & $3.5 \pm 0.84$ & $4.0 \pm 0.82$ & $0.001^{* *}$ \\
\hline $\begin{array}{c}\text { Side of fractured rib } \\
\text { Unilateral } \\
\text { Bilateral }\end{array}$ & $\begin{array}{c}29(90.6 \%) \\
3(9.4 \%)\end{array}$ & $\begin{array}{c}6(100 \%) \\
0\end{array}$ & $\begin{array}{c}4(100 \%) \\
0\end{array}$ & 0.859 \\
\hline
\end{tabular}

Table 3: Distribution of chest injuries associated with flail chest injury in patients admitted to Menoufia University Hospital.

\begin{tabular}{|c|c|c|c|}
\hline & $\begin{array}{c}\text { RTA } \\
\mathbf{N = 3 2}\end{array}$ & $\begin{array}{c}\text { Fall } \\
\mathbf{N = 6}\end{array}$ & $\begin{array}{c}\text { Assault } \\
\mathbf{N = 4}\end{array}$ \\
\hline Haemothorax & $8(25 \%)$ & $3(50 \%)$ & $1(25 \%)$ \\
\hline Pneumothorax & $4(12.5 \%)$ & 0 & $2(50 \%)$ \\
\hline Hemopneumothorax & $7(21.9 \%)$ & $2(33.3 \%)$ & 0 \\
\hline Lung contusion & $13(40.6 \%)$ & $1(16.7 \%)$ & $1(25 \%)$ \\
\hline
\end{tabular}

Table 4: Chi square statistical analysis offlail chest injury patients admitted to Menoufia University Hospital regarding ICU, hospital stay and Outcome.

\begin{tabular}{|c|c|c|c|c|}
\hline & $\begin{array}{c}\text { RTA } \\
\mathbf{N}=\mathbf{3 2}\end{array}$ & $\begin{array}{c}\text { Fall } \\
\mathbf{N = 6}\end{array}$ & $\begin{array}{c}\text { Assault } \\
\mathbf{N}=\mathbf{4}\end{array}$ & p-value \\
\hline ICU stay (days) & $6.75 \pm 3.75$ & $5.33 \pm 1.37$ & $2.25 \pm 0.96$ & $0.05^{*}$ \\
\hline Hospital stay (days) & $13.66 \pm 4.59$ & $9.5 \pm 1.64$ & $9 \pm 0.82$ & $0.02^{*}$ \\
\hline Return to work (weeks) & $4.47 \pm 1.08$ & $3.67 \pm 0.82$ & $3.25 \pm 0.50$ & $0.03^{*}$ \\
\hline Chest wall Deformity & $10(90.9 \%)$ & $1(9.1 \%)$ & $0(0 \%)$ & 0.35 \\
\hline Mortality & $9(100 \%)$ & $0(0 \%)$ & $0(0 \%)$ & 0.17 \\
\hline
\end{tabular}

Table 5: Chi square statistical analysis offlail chest injury patients admitted to Menoufia University Hospital regarding The New injury severity score (NISS) and the mechanism of injury.

\begin{tabular}{|c|c|c|c|c|c|}
\hline \multirow{2}{*}{ NISS } & \multicolumn{3}{|c|}{ Mechanism } & \multirow{2}{*}{ P value } \\
\cline { 2 - 5 } & RTA & Fall & Assault & Total & \multirow{2}{*}{$0.03^{*}$} \\
\cline { 1 - 4 } Critical (25-75) & $21(65.6 \%)$ & $1(16.67 \%)$ & $0(0 \%)$ & $22(52.38 \%)$ & \\
\hline Serious (9-15) & $2(6.25 \%)$ & $2(33.33 \%)$ & $1(25 \%)$ & $5(11.90 \%)$ & \\
\hline Severe (16-24) & $9(28.13 \%)$ & $3(50 \%)$ & $3(75 \%)$ & $15(35.71 \%)$ & \\
\cline { 1 - 4 } Total & 32 & 6 & 4 & 42 & \\
\hline
\end{tabular}


Table 7:Chi square statistical analysis ofthe relation between flail chest injury mortality and NISS.

\begin{tabular}{|c|c|c|c|c|c|}
\hline & \multicolumn{3}{|c|}{ NISS } & \\
\hline Mortality & $\begin{array}{c}\text { Critical } \\
(\mathbf{2 5 - 7 5 )}\end{array}$ & $\begin{array}{c}\text { Serious } \\
\mathbf{( 9 - 1 5 )}\end{array}$ & $\begin{array}{c}\text { Severe } \\
\mathbf{( 1 6 - 2 4 )}\end{array}$ & Total & P value \\
\hline Yes & $8(88.9 \%)$ & $0(0 \%)$ & $1(11.1 \%)$ & $9(21.4 \%)$ & $0.045 *$ \\
\hline
\end{tabular}

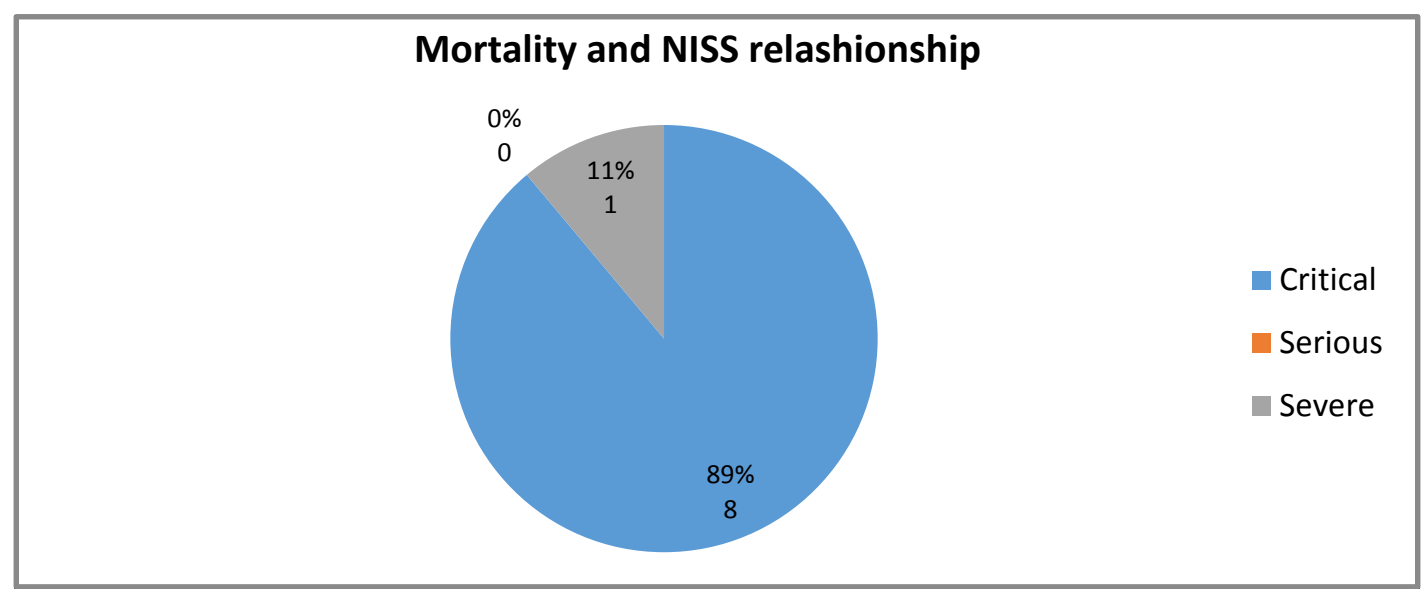

Figure 1:Pie chart illustrating the relation between Mortality due to flail chest injury and NISS

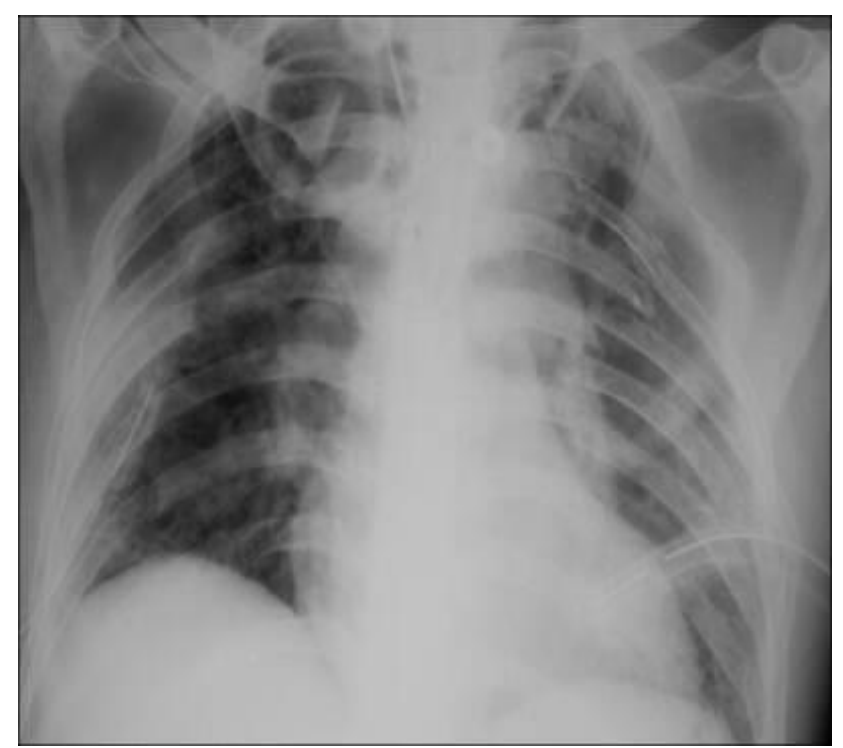

Figure 2: Plain chest $X$ ray postro-anterior view showing multiple fracture ribs on the left side causing a postro-lateral flail segment.

\section{Discussion}

Flail chest injury is a serious life-threatening condition occurs as a result of application of high force to the chest wall. In this study, the flail chest injury represented $8.2 \%$ of all blunt chest trauma admitted to Menoufia University Hospital during the period of study. While its incidence is $10 \%$ to $15 \%$ of severe chest trauma in the United States (Vijay Kumar et al., 2011).

In the present study, it was found that age had no significant correlation with the cause of flail chest trauma, while Albaugh et al., (2000)found that age is the strongest predictor of flail chest trauma outcome

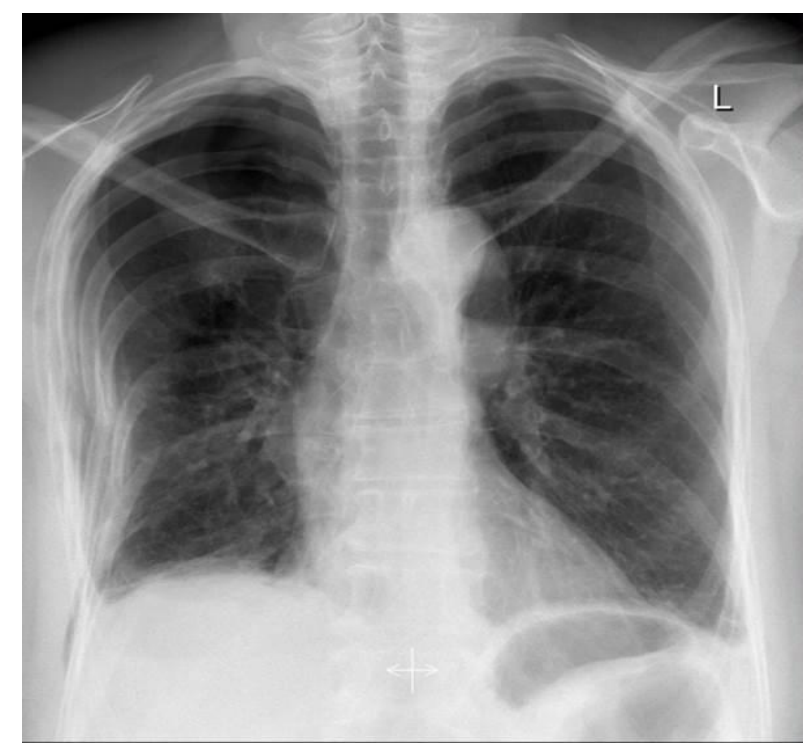

Figure 3: Plain chest $\mathrm{X}$ ray postro-anterior view showing multiple fracture ribs on the right side causing a right lateral flail segment

andis associated with an increased mortality.Athanassiadi et al., (2010) found that no correlation between trauma and age which had been agreed with our study.

As regards gender; males were exposed to trauma more than female (76.19\% male, $23.81 \%$ female), as they are more actively participating in heavy jobs and in sports activity. This was also found in a previous study of Caragounis et al., (2016).

It was observed that the most common leading cause of flail chest injury in our study was road traffic accident (RTA) followed by fall and lastly assault. This 
was in agreement withAthanassiadi et al., (2010)and Taylor et al., (2016) who found that RTA is the leading cause of traumatic flail chest injury. In a study done by Sirmali et al., (2003) , they found that the main etiology of chest trauma was road traffic accidents followed by fall, assault, and industrial accidents.In the present study, crashes between vehicles and pedestrians are responsible for more than half of all RTA cases Compared with vehicle occupant casualties, this was in agreement with Dalia Zaki et al., (2006)who found that more than half of RTA victims were pedestrians (57.9\%),AlMiadani and Al Janahi, (2006)also reported that pedestrians sustain more multiple injuries, with higher injury severity scores and higher mortality rates.

There was a high significant difference between the cause of injury and the number of fractured ribs, as the largest number of fractured ribs was observed in RTA group (9.4\% of cases had bilateral rib fractures) which indicates the severity of RTA trauma and this may be due to the high impact force to the chest wall and large striking surface area in RTA,while the least number of fractured ribs was in assault,all of which were unilateral, as the injuries occur from direct transfer of a limited amount of impact energy to the chest region, Dragu, et al ( 2009) reached the same conclusion.

Criteria of rib fractures could differentiate the cause of injury either due to RTA, falls or assaults. As unilateral rib fracturemostly caused by force that is less severe than that causing bilateral multiple rib fractures (Dragu, et al 2009).

As regards the associated intra thoracic injuries in the present study, lung contusion was the most common one (35.7\%) followed by haemothorax (28.57\%), followed by hemopneumothorax (21.43\%) and pneumothorax (14.29\%).These comply withAthanassiadi et al, (2010) who observed a lung contusion in $78 \%$ of the traumatic patients while pneumothorax and haemothorax presented in $28 \%$ and $33 \%$ respectively.

In relation to the mechanism of trauma, in RTA, lung contusion represented the highest incidence (40.6\%); however, in the fall cases, haemothorax formed the highest incidence; pneumothorax represented $50 \%$ of assault cases. Dragu et al.,(2009)also reported lung contusion in $72 \%$ of RTA cases, $17.1 \%$ of fall cases and no evidence of pulmonary contusion in cases of assault.

Regarding the duration of ICU stay and hospital stay in this study, it was found that patients who came in RTA stayed longer, this indicates that the injury severity was higher in the RTA. It was observed by Battle and Evans, (2015)that the length of hospital stay can be used to predict the mortality in flail chest injury patients.Albaugh et al, (2000) also reached the same conclusion; on the other hand, Athanassiadi et al, (2010) reported that ICU stay was not significant in determining the mortality.

Mortality rate was $21.4 \%$ from the total flail chest cases, all of them were due to RTA. In another study done by Kumar and his associate on patients with rib fractures in 2012, the mortality rate was $20.18 \%$. But it was only 5.3\% with Athanassiadi et al., (2004).

The severity of injuries in this study was graded according to the new injury severity score (NISS) as it is more predictive of survival (Stevenson et al., 2001).

Nearly $89 \%$ of the dead cases were classified as critical cases according to the NISS, so patients with high NISShad a high mortality rate, this was agreed with Hamed et al., (2010) who stated that the NISS was significantly higher in non-survivors. Also, this result was in agreement with Athanassiadi et al., (2010), who found that the severity scoring of the injury was the strongest predictor of theoutcome.

\section{Conclusion}

Flail chest injury represents a serious lifethreatening condition with multiple associated injuries, it represented $8.2 \%$ of all blunt chest trauma admitted to Menoufia University Hospital during the period of thestudy. RTA is the most common cause of flail chest injury. The cause of the injury could be predicted from the criteria of the trauma. Bilateral rib fracture, presence of lung contusion and long period of stay in hospital is all a sign of severe trauma, while the NISS is considered a significant way for prediction of the mortality rate among the flail chest trauma patients.

\section{Conflicts of interest}

The authors declare that they have no conflicts of interest in this research.

\section{References}

Albaugh G, Kann B, Puc M and et al (2000) 'Ageadjusted outcomes in traumatic flail chest injuries in the elderly', the American Surgeon, 66(10), p. 978-81.

Allen GS and Coates NE (1996) 'Pulmonary contusion a collective review', Am Surg. , 62, pp. 895900.

Al Madani A and Al Janahi M: personal exposure risk factors in pedestrian accidents in Bahrain, Safety Science 44: 335-347, 2006.

Athanassiadi, K., Gerazounis, M. and Theakos, N. (2004) 'Management of 150 flail chest injuries: analysis of risk factors affecting outcomes, European Journal of CardioThoracic Surgery. Oxford University Press, 26(2), pp. 373-376. doi: 10.1016/j.ejcts.2004.04.011.

Athanassiadi, K., Theakos, N., Kalantzi, N. and Gerazounis, M. (2010) 'Prognostic factors in flail-chest patients 2 ', European Journal of Cardio-Thoracic Surgery, 38(4), pp. 466-471. doi: 10.1016/j.ejcts.2010.02.034.

Baker SP, O'Neill B, Haddon W, et al.(1974) :The Injury Severity Score: a method for describing patients with multiple injuries and evaluating emergency care. J Trauma. ;14:187-196

Balogh ZJ, Varga E, Tomka J, et al.( 2003): The New Injury Severity Score is a better predictor of extended hospitalization and intensive care unit admission than the Injury Severity Score in patients with multiple orthopaedic injuries. J Orthop Trauma.;17:508-512 
Battle, C. E. and Evans, P. A. (2015) 'Predictors of mortality in patients with flail chest: a systematic review', Emergency Medicine Journal, 32(12), pp. 961-965. doi: 10.1136/emermed-2015-204939.

Caragounis, E.-C., Fagevik Olsén, M., Pazooki, D. and Granhed, H. (2016) 'Surgical treatment of multiple rib fractures and flail chest in trauma: a one-year follow-up study.', World journal of emergency surgery: WJES. BioMed Central, 11, p. 27. doi: 10.1186/s13017-016-0085-2.

Ciraulo DL, Elliott D, Mitchell KA and Rodriguez A (1994) 'Flail chest as a marker for significant injuries', J Am Coll Surg , 178(5), pp. 466-70.

Coughlin, T. A., Ng, J. W. G., Rollins, K. E., Forward, D. P. and Ollivere, B. J. (2016) 'Management of rib fractures in traumatic flail chest: a metaanalysis of randomised controlled trials.', The bone \& joint journal, 98-B(8), pp. 1119-25. doi: 10.1302/0301-620X.98B8.37282.

Dragu, M., Salem, A. and Marinescu, M. (2009) 'Forensic assessment of blunt thoracic trauma - correlations between pattern of injuries and trauma dynamics', Romanian Journal of Legal Medicine, 17(2). doi: 10.4323/rjlm.2009.122.

Evman, S., Kolbas, I., Dogruyol, T. and Tezel, C. (2015) 'A Case of Traumatic Flail Chest Requiring Stabilization with Surgical Reconstruction.', The Thoracic and cardiovascular surgeon reports. Thieme Medical Publishers, 4(1), pp. 8-10. doi: 10.1055/s-0035-1558433.

Hamed, G., Omar, E., Abd El-bary, A. and El-deen Sayed, S. (2010) 'The Utility of Trauma Scoring Systems in Outcome Prediction of Critical Patients', Med. J. Cairo Univ, 78(2), pp. 669-674.

Marasco, S. F., Davies, A. R., Cooper, J., Varma, D., Bennett, V., Nevill, R., Lee, G., Bailey, M. and Fitzgerald, M. (2013) 'Prospective Randomized Controlled Trial of Operative Rib Fixation in Traumatic Flail Chest', Journal of the American College of Surgeons. Australian Bureau of Statistics, Canberra, ACT, 216(5), pp. 924-932. doi: 10.1016/ j. jamcollsurg. 2012.12.024.

Osler, T., Baker, S. P. and Long, W. (1997) 'A Modification of the Injury Severity Score That Both Improves Accuracy and Simplifies Scoring', The Journal of Trauma: Injury, Infection, and Critical Care, 43(6), pp. 922926. doi: 10.1097/00005373-19971200000009.

Sırmalı, M., Türüt, H., Topçu, S., Gülhan, E., Yazici, Ü., Kaya, S. and Taştepe, I. (2003) 'A comprehensive analysis of traumatic rib fractures: morbidity, mortality and management', European Journal of CardioThoracic Surgery. Oxford University Press, 24(1), pp. 133-138. doi: 10.1016/S10107940(03)00256-2.

Stevenson, M., Segui-Gomez, M., Lescohier, I., Di Scala, C. and McDonald-Smith, G. (2001) 'An overview of the injury severity score and the new injury severity score.', Injury prevention : journal of the International Society for Child and Adolescent Injury Prevention. BMJ Group, 7(1), pp. 10-3. doi: 10.1136/ip.7.1.10.

Taylor, B. C., Fowler, T. T., French, B. G. and Dominguez, N. (2016) 'Clinical Outcomes of Surgical Stabilization of Flail Chest Injury', Journal of the American Academy of Orthopaedic Surgeons, 24(8), pp. 575-580. doi: 10.5435/JAAOS-D-15-00476.

Vijay Kumar AG, S. M., MG, S., U, K., KC, S. and Hallikeri, A. K. T. and V. R. (2011) 'The Comprehensive Analysis of Traumatic Rib Fractures and their Complications: A Post Mortem Study', Journal of Forensic Research. OMICS International, s2(1). doi: 10.4172/2157-7145.S2-004.

Zaki D., Shalaby S., Abdel Monem Y., Fouda M., (2008)' Medico-legal Aspects of some road traffic injuries in great Cairo, Ain Shams University journal. PP 113. 
الملخص العربيى

\section{نمط إصابات الصدر السائب الجرحيه الناتجه عن الاصابات الراضه بالصدر في مستشفي جامعه المنوفيه (دراسه مستقبليه)}

\section{علا عبد الهادي منصور و ريهام حسن الفرعوني}

المقدمة: يعتبر الصدر السائب الناتج عن الاصابه بواسطه اله صلبه راضه من الإصابات التي ينتج عنها مضاعفات خطيرة وقد تؤدي

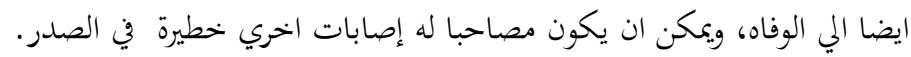
الهدف من العمل: دراسه انماط إصابات الصدر السائبو تحديد العوامل المؤثره علي إصابات الصدر السائب في الحالات الوات الوارده لمستشفي جامعه المنوفيه من عوامل لها صله بالمصاب او الاصابه نفسها والنتائج المترتبة علي ذلك.

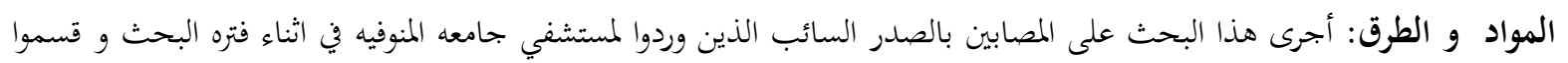

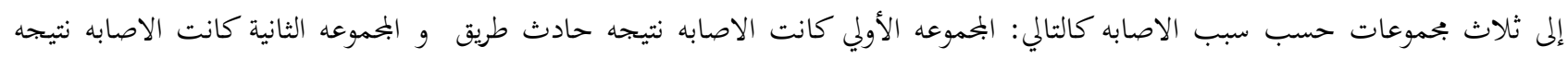

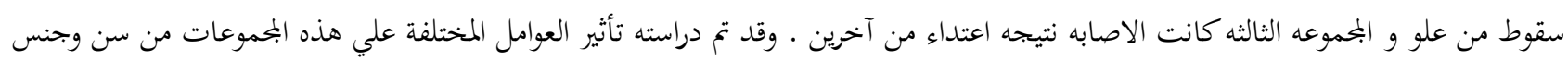

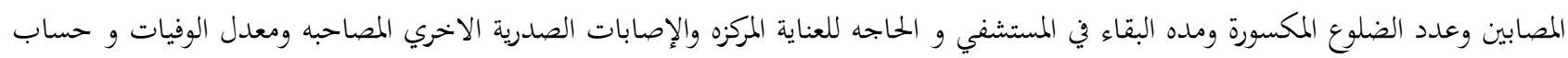

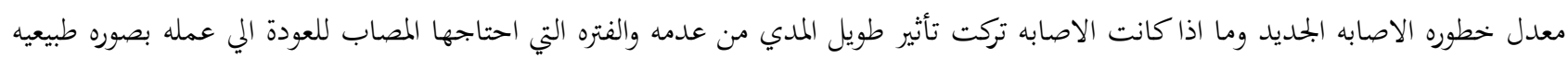
مره اخري.

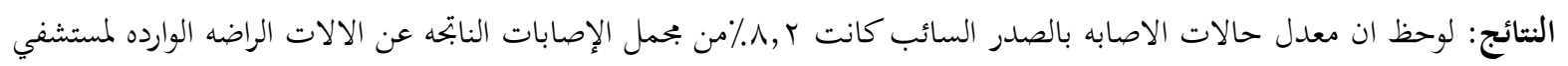

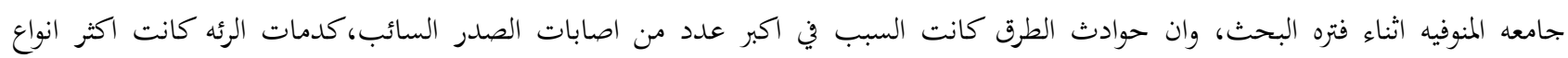

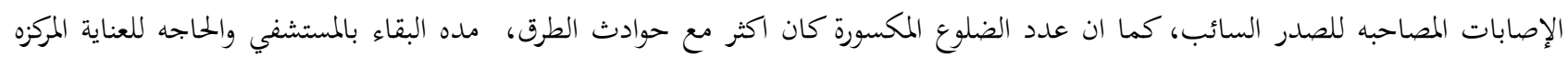

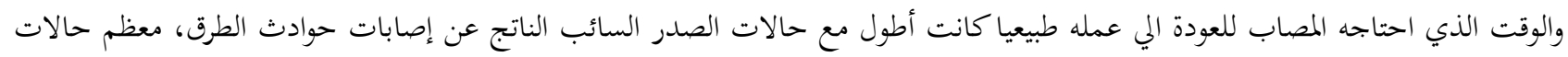

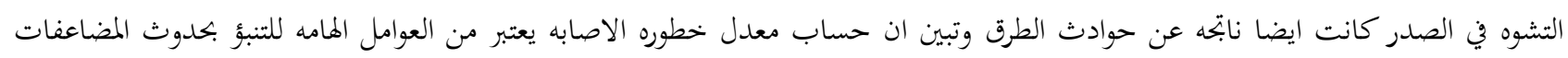

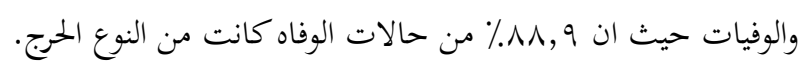

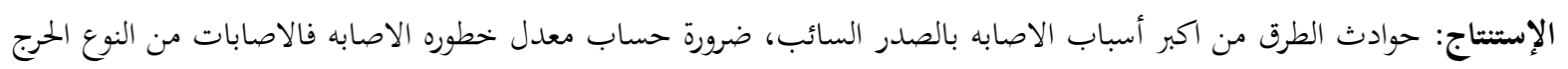
هي اكثر الإصابات التي تؤدي الي الوفاه. 